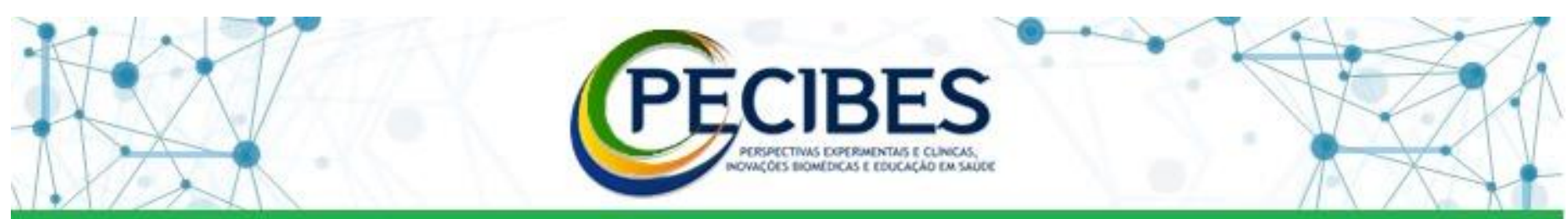

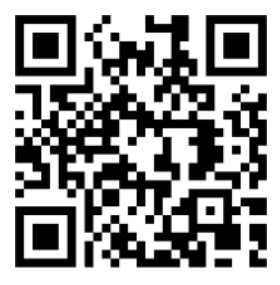

http://www.seer.ufms.b r/index.php/pecibes/ind ex

* Autor correspondente: Karina Ayumi Martins Utida, Universidade Federal de Mato Grosso do Sul UFMS.

karina.utida@ufms.b $\mathrm{r}$

Key-words: Extreme conditioning programs.

Prevalence. Injury.

Descritores:

Programas

de condicionamento extremo.

Prevalência.

Lesões.

\section{Caracterização de lesões esportivas ocorridas durante o período de pandemia por COVID-19 em Programas de Condicionamento Extremo.}

Characterization of sports injuries common to COVID-19 pandemic period in Extreme Conditioning Programs

Karina Ayumi Martins Utida ${ }^{1}$; Denise Cruz Carvalho Gomes²; Fábio de Souza Ajala²; Paula Felippe Martinez ${ }^{3}$; Silvio Assis de Oliveira-Júnior ${ }^{3}$.

1. Fisioterapeuta, doutoranda no Programa de Pós-Graduação em Saúde e Desenvolvimento na Região Centro-Oeste, Faculdade de Medicina/Universidade Federal de Mato Grosso do Sul (UFMS), Brasil.

2. Estudante do Curso de Graduação em Fisioterapia, Instituto Integrado de Saúde (INISA)/UFMS, Brasil.

3. Fisioterapeuta. Doutor(a), docente do Curso de Graduação em Fisioterapia, INISA/ UFMS, Brasil.

Introdução: Programas de condicionamento extremo (PCE) compreendem uma modalidade de treinamento físico que tem recebido importante atenção por abranger atividades multiarticulares que resultam em aumento de força e resistência. Objetivo: investigar a prevalência e descrever as lesões esportivas em praticantes de PCE. Material e métodos: A casuística foi constituída por praticantes de PCE de três academias de diferentes regiões urbanas da cidade de Campo Grande/MS. Foram incluídos 156 participantes de ambos os sexos, com idade de 32,7 $\pm 6,9$ anos, sendo a maioria do sexo feminino $(n=89 ; 57,1 \%)$. A carga horária média de treino era de 5,5 $\pm 2,4$ horas semanais e o tempo de prática em PCE foi de 32,5 $\pm 19,9$ meses. Os participantes foram abordados e entrevistados nos próprios locais de treinamento. Para a tomada de informações, foi utilizado um questionário estruturado, com foco na prevalência de lesões ocorridas nos últimos 12 meses e que incluía dados demográficos e dados de treinamento. O presente estudo foi aprovado pelo Comitê de Ética em Pesquisa (CEP/ UFMS), sob CAAE 42946420.0.0000.0021. Os resultados são apresentados na forma descritiva. Resultados: A prevalência geral de lesões foi de $28,8 \%$ (45 participantes) sendo que, destes, $17,8 \%$ (oito participantes) relataram duas lesões no período, totalizando 53 lesões reportadas. A prevalência segundo o sexo foi de 40,3\% $(n=27)$ entre os homens e 20,2\% $(n=18)$ entre as mulheres. A incidência de lesões foi de 1,18 lesões/1000 horas. Considerando-se o local de acometimento, a maioria dos casos envolveu os membros superiores $(58,5 \% ; n=31)$, seguido de agravos nos membros inferiores e no tronco $(39,6 \% ; \mathrm{n}=21 \mathrm{em}$ ambos). Mais da metade das lesões em membros superiores ocorreram no ombro $(54,8 \% ; \mathrm{n}=17)$. Entre os relatos de lesões, a maioria procurou atendimento fisioterapêutico $(58,5 \% ; n=31)$. Conclusões: A prevalência de lesões entre praticantes de PCE foi de $28,8 \%$, sendo maior no sexo masculino, principalmente situadas nos membros superiores, nos ombros e a maioria dos praticantes procurou atendimento fisioterapêutico. 